\section{Cultural Prototypes and Dimensions of Honor}

\author{
Susan E. Cross', Ayse K. Uskul ${ }^{2}$, Berna Gerçek-Swing', Zeynep \\ Sunbay $^{3}$, Cansu Alözkan ${ }^{3}$, Ceren Günsoy', Bilge Ataca ${ }^{4}$, and \\ Zahide Karakitapoğlu-Aygün ${ }^{5}$
}

Personality and Social

Psychology Bulletin

2014, Vol. 40(2) 232-249

(C) 2013 by the Society for Personality and Social Psychology, Inc

Reprints and permissions: sagepub.com/journalsPermissions.nav DOI: $10.1|77 / 0| 46 \mid 67213510323$ pspb.sagepub.com

\begin{abstract}
Research evidence and theoretical accounts of honor point to differing definitions of the construct in differing cultural contexts. The current studies address the question "What is honor?" using a prototype approach in Turkey and the Northern United States. Studies Ia/lb revealed substantial differences in the specific features generated by members of the two groups, but Studies 2 and 3 revealed cultural similarities in the underlying dimensions of self-respect, moral behavior, and social status/respect. Ratings of the centrality and personal importance of these factors were similar across the two groups, but their association with other relevant constructs differed. The tripartite nature of honor uncovered in these studies helps observers and researchers alike understand how diverse responses to situations can be attributed to honor. Inclusion of a prototype analysis into the literature on honor cultures can provide enhanced coverage of the concept that may lead to testable hypotheses and new theoretical developments.
\end{abstract}

\title{
Keywords
}

honor, prototypes, social status, lay conceptions

Received October 18, 2012; revision accepted September 18, 2013

In much of the Northern United States and Western Europe, the concept of honor is often invoked in set phrases such as "it is my honor to ... " but it is not encountered or referenced widely in everyday life (Wikan, 2008). In other contexts, such as Turkey, other parts of the Mediterranean region, and Latin America, honor has a very extensive role in social life; it is invoked as the primary goal of life (Kardam, 2005) as well as the motivation for socially valued (e.g., acting honestly) and destructive behaviors (e.g., honor killings). Although considerable research has investigated honorrelated behaviors cross-culturally, the question of cultural similarities and differences in the definition or meaning of honor is seldom addressed (for an exception, see Rodriguez Mosquera, Manstead, \& Fischer, 2002a). The current studies examine the lay prototypes associated with the concept of honor in cultures from Western (the Northern United States) and Mediterranean (Turkey) regions, as a step toward understanding similarities and differences in the ways honor motivates behavior in these societies.

\section{Honor in Cultural Contexts}

The concept of an "honor culture" was first articulated by anthropologists studying Mediterranean societies (PittRivers, 1965). Nisbett and Cohen (1996) argue that in honor cultures, people must acquire reputations for being trustworthy and likely to reciprocate positive treatment (such as hospitality) and wrongdoings (through vengeance). The person who fails to behave according to the honor code, which spells out acceptable behavior, or who has no concern for the opinions of others, is viewed as untrustworthy, loses stature in the community, and may incur many other tangible and intangible costs. In contrast, in nonhonor (or dignity) cultures, the individual is assumed to have inherent worth that is equal to every other person's worth and that cannot be taken away by others (Leung \& Cohen, 2011). Internal standards and goals rather than social expectations are the ideal motivators of good behavior. Thus, compared with members of honor cultures, members of dignity cultures are less concerned about reputation or reciprocity and

\footnotetext{
'lowa State University, Ames, USA

${ }^{2}$ University of Kent, UK

${ }^{3}$ Istanbul Bilgi University, Turkey

${ }^{4}$ Boğaziçi University, Istanbul, Turkey

${ }^{5}$ Bilkent University, Ankara, Turkey

Corresponding Author:

Susan E. Cross, Department of Psychology, WII 2 Lagomarcino Hall, lowa State University, Ames, IA 500 I I, USA.

Email: scross@iastate.edu
} 
are more likely to overlook slights or insults (e.g., Cohen, Nisbett, Bowdle, \& Schwarz, 1996).

Recent sociopsychological research suggests that cultures differ not only in how honor is defended and maintained (e.g., Cohen et al., 1996; Rodriguez Mosquera, Fischer, Manstead, \& Zaalberg, 2008; Vandello, Cohen, Grandon, \& Franiuk, 2009) but also in how it is understood and conceptualized. For example, in a study where Spanish and Dutch participants responded to the question "What does honor mean to you?" Rodriguez Mosquera et al. (2002a) found that Dutch participants were more likely than Spaniards to generate items related to positive feedback for accomplishments and one's achievements, whereas Spanish participants were more likely than Dutch to generate items related to behaving interdependently. There were no cultural differences in frequencies of items coded into categories reflecting one's sense of worth or one's socioeconomic status (SES). When Uskul, Cross, Sunbay, Gerçek-Swing, and Ataca (2012) asked Turkish and Northern U.S. participants to describe situations that would threaten or enhance one's honor, their responses differed on several dimensions: Compared with the Northern U.S. situations, the Turkish situations were more likely to refer to false accusations, unfair treatment, or physical or sexual attacks. In contrast, the Northern U.S. situations were more likely to focus on criticizing a person's ideas or character or on revealing a person's lack of integrity. When asked about situations that would enhance a person's honor, Turkish participants were more likely than Americans to report situations in which an individual accomplished something positive, whereas Americans were more likely to describe situations in which a person helped others. These differences suggest that the cognitive representations of honor may differ in these two groups.

Theoretical conceptualizations of honor also differ. Bowman (2006) defines honor as "the good opinion of the people who matter to us ... [because they] have the power to judge our behavior" (p. 4). Salzman (2008) also focused on honor as "public opinion's judgment of one's actions" (p. 105), but he emphasized the importance of one's place in the social dominance hierarchy as key to understanding honor (see also Henry, 2009). Some scholars have focused on reciprocity (of good deeds and bad) as the key element of an honor culture (Miller, 1993; Nisbett \& Cohen, 1996). Others have articulated a dual theory of honor including the individuals' feelings of self-worth and their social recognition by others (Pitt-Rivers, 1965; Wikan, 2008).

Thus, the research literature and theoretical expositions indicate that there are diverse definitions of honor and its key features. The aim of the current studies is to use a systematic approach - the lay prototypes approach (Fehr, 1988; Fehr \& Russell, 1991) - to investigate everyday conceptions of honor in two cultural contexts. An understanding of the lay prototypes of honor can help scientists better grasp the critical components of the phenomenon and what people mean when they act in the name of honor. For example, in the
Istanbul uprisings of the summer of 2013 over the government's plans to raze Gezi Park, both the protestors and the government, who used force against the protestors, claimed to be partly motivated by honor (Oz, 2013; "Turkish President Warns," 2013). This suggests that the everyday conceptions of honor in Turkey may have diverse components that can motivate quite different behaviors. Examination of lay conceptions of honor can identify biases or hidden assumptions in the existing research, and lay conceptions can be used to assess competing theories (Fehr, 2005). Finally, the specific features and dimensions of the construct identified through a prototype analysis can contribute to the refinement of measurement tools.

In this work, we use a prototype approach to uncover the content and structure of the layperson's conceptions of honor in Turkey and in the Northern United States. In contrast to the classic understanding of category membership, a prototype approach acknowledges that many categories have fuzzy boundaries and that some features of category membership are more central to the understanding of the category than other features (Rosch, 1975). As Fehr (2005) notes, much of the research using a prototype approach has attempted to answer the "What is it?" question. For example, researchers have investigated prototypical conceptions of love (Fehr, 1994), forgiveness (Kearns \& Fincham, 2004), and modesty (Gregg, Hart, Sedikides, \& Kumashiro, 2008). The prototype approach has also been used to identify similarities and differences between related constructs, such as love and commitment (Fehr, 1988). Once the prototypical features of a concept have been identified, one can also examine whether a meaningful set of dimensions underlies those features (Aron \& Westbay, 1996; Hassebrauck \& Fehr, 2002). These dimensions can be compared with experts' theories and may either confirm them or reveal overlooked components of the concept (Aron \& Westbay, 1996; Fehr \& Russell, 1991).

Although the empirical evidence and existing theories of honor indicate differences in the lay prototypes of honor in Turkey and in the Northern United States, it is possible that the types or degree of differences depend on the level of analysis. First, differences may be found at the level of the basic features of the prototype; members of the two cultural groups could generate quite different terms relevant to the construct of honor, or they could generate similar terms but evaluate their centrality to the prototype differently. Second, examination of the latent structure of the prototypicality of the features could reveal a similar or different structure in the two groups, as well as similar or different associations between the latent dimensions for the groups. Finally, even if a similar latent structure is found for the prototypical features in the two groups, the associations of the dimensions with other constructs may differ between the cultural groups. There may be some deep structure central to the conceptualization of honor that is shared in the two groups, but the cultures may differ in the degree to which they emphasize, recognize, or act on different aspects of this shared structure. 
The investigation of lay prototypes has great research promise across cultures, but to date, it has been seldom used to address culture comparative questions. Other researchers have used a prototype approach to examine whether the structure of a set of concepts (e.g., emotion terms) identified in one culture can also be found in other cultures (Hassebrauck \& Fehr, 2002; Shaver, Murdaya, \& Fraley, 2001; Shaver, Wu, \& Schwartz, 1992). Our investigation revealed only one other study (Smith, Turk Smith, \& Christopher, 2007) that concurrently examined the prototypical features of a concept across different cultures; these authors did not, however, investigate the latent structure of the prototype. Thus, the present studies are the first to use a prototype approach to identify cultural similarities and differences in the features of a prototype and to search for meaningful dimensions underlying that prototype.

\section{Overview of Studies}

This research used the prototype approach to identify the content and structure of Turkish and Northern American conceptions of honor and to compare these conceptions across the two cultural groups. Honor is a core value in Turkish society (Kardam, 2005), but Turkey differs importantly from the countries in which most psychological research on honor is conducted. Turkey is a collectivist culture with an Islamic heritage, in contrast to the Protestant or Catholic worldviews that have shaped individualistic European and American societies. In addition, relatively little contemporary research in social psychology has focused on Southeast European/ Middle Eastern societies; so, this research expands honor research to a new region and religion.

Four primary goals guided our studies: (a) to identify the central and peripheral features of honor as reported by lay people in the Northern United States and Turkey; (b) to investigate whether there are meaningful underlying dimensions to those features; (c) to test whether these dimensions, if found, differ across the two cultures; and (d) if meaningful dimensions of honor are found, to examine their associations with other theoretically related measures.

\section{Studies I a and Ib}

The purpose of Study 1 was to first to compile the features of the prototype of honor in each cultural context and then to have participants identify the features that are more or less central to the prototype. Following the methods defined by Fehr (1988, 1994), in Study 1a, we first asked Turkish and Northern American participants of European background to generate all the features of honor they could, using a freeresponse format. Trained coders combined conceptually similar features to create a smaller list of meaningful features. We examined the average number of features generated by members of each group as well as overlap in the features generated. In Study 1b, another group of participants in each cultural group rated the features generated by their co-nationals for their centrality to the concept of honor. Highly prototypical features are defined as those that are frequently mentioned in Study 1a and rated as highly central in Study $1 b$.

\section{Study la Method}

Participants. The Turkish sample consisted of 84 (56 women) undergraduates from a large public university in Istanbul. The Northern American sample consisted of 106 (52 women) European American undergraduates from a public northern university. Participants in all studies participated in groups of 5 to 20 and received course credit for their participation.

Procedure. To make conceptions of honor salient for participants, they were first asked to think for a minute about the ways that the word "honor" is used. They then responded to two open-ended questions: (a) What comes to your mind when you think of an individual's personal honor? (b) What does it mean to be a person with honor? These questions were presented as part of a larger study on the meaning of honor.

We carefully selected the Turkish term onur as a translation of the term honor in English, because other honor researchers have suggested that it is the most similar in meaning to the Northern North American understanding of honor (see Sev'er \& Yurdakul, 2001). Moreover, onur is gender neutral in its usage, unlike many other possible Turkish translations of honor. Following procedures used by other researchers who worked with particular concepts in different languages (e.g., Smith et al., 2007), the team fluent in Turkish and English who translated and backtranslated instructions and questionnaires also agreed that the terms onur and honor were the closest in meaning in the two languages. Thus, cross-cultural differences in responses are unlikely to occur due to a construct bias introduced by the use of two different terms in this multilingual cross-cultural research.

Included in this study (and in all the subsequent studies) were questions about age, family SES $(1=$ very poor to $9=$ very wealthy), and religious devotion $(1=$ not at all devout to 9 = extremely devout). The analysis of cultural differences in these measures is provided in a footnote. ${ }^{1}$

\section{Results and Discussion}

Turkish participants appeared to have more complex representations of honor than did Northern Americans. Turkish participants generated an average of 7.42 individual features $(S D=3.2)$, whereas Northern Americans generated an average of 4.97 features $(S D=2.49), t(190)=5.96, p<.001, d=$ 85 . To create a list of unique features of honor, two bilingual coders examined the Turkish responses; one bilingual and two English speakers examined the Northern American responses. Following the procedure described by Fehr 
(1988), coders divided the open-ended responses into meaningful linguistic units (e.g., "someone who is faithful and loyal" includes two linguistic units: (a) someone who is faithful, (b) someone who is loyal). First, monolexemic responses such as "honest" were grouped together. Then, these features were aggregated into larger groups. Phrases such as someone's honesty were included with the corresponding monolexemic category (e.g., honest). Words that were judged to be synonymous (e.g., brave and courageous) were grouped together. Words that were similar in meaning but not synonymous were kept separate (e.g., honesty and truthfulness). Second, phrases with qualifiers and adjectives, as well as descriptions of particular situations and behaviors, were carefully examined. Phrases that were very similar in meaning were grouped together (e.g., the phrases Someone who does good things and To do something good were grouped into the general feature of "Doing good things"). When a qualifier was judged to create a different feature, it was kept separate (e.g., accomplishments and taking pride in accomplishments were treated as different features). Consistent with Fehr's procedure, idiosyncratic features mentioned by only one person were dropped from further analysis. This resulted in 70 Turkish and 75 Northern American unique features.

Tables 1 and 2 present the features generated by Turkish and Northern American participants, respectively, ordered by frequency. Most notable are the differences in the frequencies of the most common features. In the Turkish sample, the most commonly mentioned feature of honor is honesty, generated by $40 \%$ of the participants, followed by namus, generated by $20 \%$ of the participants. ${ }^{2}$ In contrast, the most frequently mentioned Northern American features-doing the right thing and being respected-were mentioned by only $15 \%$ of the sample. Thus, a greater proportion of Turkish participants agreed on the specific features of honor compared with the American participants. ${ }^{3}$

We also examined the overlap in the features generated by Turkish and Northern American participants using the index of inter-prototype similarity (Cantor, Mischel, \& Schwartz, 1982). This index is the ratio of shared to unique attributes in pairs of descriptor lists, and in the Cantor et al. (1982) study of prototypes of situations, the similarities ranged from .00 to 1.30. Sixteen features (indicated in bold in Tables 1 and 2) were generated by participants in both samples (e.g., being respected, honesty), resulting in a ratio of .14, which represents a fairly low level of similarity in the two lists. Thus, there were substantial differences in the features of honor generated by Turkish and Northern American participants.

One of the interesting differences in the features mentioned by these two groups was in the degree to which they mentioned what one should not do (e.g., not going back on your word, not cheating). Of the features mentioned by two or more participants, 21 of $70(30 \%)$ statements by Turkish participants were phrased in the negative, whereas only 3 of 75 (4\%) statements by Northern Americans were negations, $\chi^{2}(1)=12.75, p<.001$. This finding highlights the importance of the honor code and Turkish participants' greater awareness of the ways that honor can be lost, compared with Northern American participants.

\section{Study Ib Method}

Participants. The Turkish sample consisted of 197 (146 women) undergraduates from a large public university in Istanbul. The Northern U.S. sample consisted of 249 (145 women) European American undergraduates from a public northern university.

Materials and procedure. The list of features in Tables 1 and 2 were used to create separate questionnaires for Turkish and Northern U.S. participants, who rated only the features generated by their co-nationals. Participants first read the instructions describing the concept of a prototype using examples and then were asked to rate how central the listed attributes were to their concept of having honor $(1=$ this feature is an extremely poor indicator of having honor; $7=$ this feature is an extremely good indicator of having honor). The instructions were translated and backtranslated to ensure equivalence, and the features were presented in two counterbalanced orders.

\section{Results and Discussion}

Tables 1 and 2 present the mean centrality rating of each feature. As shown there, some frequently listed features (such as to be respectable in the community in the Turkish data) were not evaluated as highly central to the concept of honor. The correlation of the rank order of these centrality ratings with their frequencies obtained in Study 1a was statistically significant for the Northern U.S. features, $r=.28, p<.02$, but only marginally significant for the Turkish features, $r=.21$, $p<.08$. Using Fisher's $r$-to- $z$ transformation, this difference was not significant, $p>.20$. These correlations are in line with the correlations found in other studies of lay prototypes (e.g., $r=.17$ for features of forgiveness, Kearns \& Fincham, $2004 ; r=.33$ for features of relationship quality, Hassebrauck, 1997). Hassebrauck (1997) suggests that an availability heuristic may influence participants' generation of the features, such that the features that come to mind easily (perhaps because of common folk sayings or proverbs) will be listed more frequently. In contrast, relatively systematic processes may drive the centrality ratings. These divergent processes may account for the relatively low correlations between frequency and centrality.

What comprises the prototypical features of honor in each group? In Turkey, the features that are high in frequency (mentioned by $7 \%$ or more) and in centrality (rated 5.5 or higher on a 7-point scale) include honesty, keeping promises, not telling lies, trustworthiness, having personal values, truthfulness, dignity, self-respect, not being a hypocrite, and 
Table I. Frequency and Importance of Features of Honor for the Turkish Sample.

\begin{tabular}{|c|c|c|}
\hline \multirow[b]{2}{*}{ Concept } & \multirow{2}{*}{$\frac{\text { Study la }}{\text { Percentage of participants }}$} & \multirow{2}{*}{$\frac{\text { Study Ib }}{\text { Centrality ratings }}$} \\
\hline & & \\
\hline Honesty & 40.00 & 6.27 \\
\hline Namus $^{2}$ & 20.00 & 4.70 \\
\hline Keeping promises & 15.29 & 6.22 \\
\hline To be respectable in the community & 15.29 & 4.36 \\
\hline To fit into the rules of the society & 15.29 & 4.27 \\
\hline Not telling lies & 14.12 & 6.01 \\
\hline Having morals & 12.94 & $5.4 I$ \\
\hline Trustworthiness & 11.76 & 6.09 \\
\hline Having personal values & 11.76 & 5.61 \\
\hline Personal characteristics & 11.76 & 5.41 \\
\hline Consistency & 11.76 & 5.30 \\
\hline To fit into general moral expectations & 11.76 & 4.77 \\
\hline Truthfulness & 10.59 & 5.92 \\
\hline Dignity & 9.41 & 5.99 \\
\hline Self-respect & 9.41 & 5.83 \\
\hline One's pride & 9.41 & 5.36 \\
\hline One's position in the society & 9.41 & 3.76 \\
\hline Not being a hypocrite & 7.06 & 6.23 \\
\hline Not to steal anything & 7.06 & 5.98 \\
\hline Being good & 7.06 & 5.49 \\
\hline Being respectful & 7.06 & 5.47 \\
\hline Being respected & 7.06 & 4.59 \\
\hline Not only thinking about oneself but also other people & 7.06 & 5.36 \\
\hline Having a clean life & 7.06 & 5.27 \\
\hline Not needing help from other people & 7.06 & 3.94 \\
\hline Not to cheat on people & 5.88 & 6.16 \\
\hline To have legitimate earnings & 5.88 & 6.00 \\
\hline An individual's personality or character & 5.88 & 5.84 \\
\hline To look out for one's own values & 5.88 & 5.55 \\
\hline Control mechanism & 5.88 & 5.13 \\
\hline Not to let oneself be oppressed by others & 5.88 & 4.82 \\
\hline Not to cause other people to talk about one's self & 5.88 & 4.50 \\
\hline Not to be unjust & 4.71 & 6.31 \\
\hline Not going back on your word & 4.71 & 6.13 \\
\hline Virtuousness & 4.71 & 5.88 \\
\hline Not causing harm to other people & 4.71 & 5.63 \\
\hline Not compromising one's own characteristics & 4.71 & 5.46 \\
\hline One's attitude toward life & 4.71 & 5.37 \\
\hline Charity & 4.71 & 4.95 \\
\hline Being mature & 4.71 & 4.92 \\
\hline Being appreciated & 4.71 & 3.72 \\
\hline Being just & 3.53 & 6.25 \\
\hline Not to let someone down & 3.53 & 6.09 \\
\hline To have values pertaining to conscience & 3.53 & 5.87 \\
\hline To have one's own principles & 3.53 & 5.52 \\
\hline Not to cause other people to talk about one's family members & 3.53 & 5.20 \\
\hline To keep one's head high & 3.53 & 4.95 \\
\hline How much the society values a person & 3.53 & 4.20 \\
\hline To be protective of others & 3.53 & 3.97 \\
\hline Not to take advantage of one's professional position to gain personal benefits & 2.35 & 6.26 \\
\hline Not to use others for one's own benefit & 2.35 & 5.79 \\
\hline
\end{tabular}

(continued) 
Table I. (continued)

\begin{tabular}{|c|c|c|}
\hline \multirow[b]{2}{*}{ Concept } & \multirow{2}{*}{$\frac{\text { Study la }}{\text { Percentage of participants }}$} & \multirow{2}{*}{$\frac{\text { Study Ib }}{\text { Centrality ratings }}$} \\
\hline & & \\
\hline To look out for humanitarian values & 2.35 & 5.76 \\
\hline Not to covet other people's possessions & 2.35 & 5.62 \\
\hline To put moral values above the material ones & 2.35 & 5.47 \\
\hline To be helpful to other people (helping others) & 2.35 & 5.32 \\
\hline Loyalty & 2.35 & 5.31 \\
\hline Not committing any crime & 2.35 & 5.28 \\
\hline The value one gives to himself or herself & 2.35 & 5.22 \\
\hline Being able to criticize oneself & 2.35 & 5.20 \\
\hline Having ethics & 2.35 & 5.13 \\
\hline To behave in appropriate ways & 2.35 & 5.07 \\
\hline Not to gossip & 2.35 & 4.96 \\
\hline Being determined & 2.35 & 4.81 \\
\hline Not to humiliate one's self & 2.35 & 4.56 \\
\hline To apply one's own virtues & 2.35 & 4.51 \\
\hline Not to be a burden on anyone & 2.35 & 4.49 \\
\hline The impression one makes on others by his or her behavior & 2.35 & 4.40 \\
\hline To fit into the customs and traditions & 2.35 & 3.46 \\
\hline To reach a certain status in the society & 2.35 & 3.45 \\
\hline Not to have one's own truths to contradict with society & 2.35 & 3.05 \\
\hline
\end{tabular}

Note. Bold text refers to concepts that were spontaneously generated by the Turkish and American participants. For the percentage of participants in the American sample, please refer to Table 2. Centrality was rated on a I- to 7-point scale.

Table 2. Frequency and Importance of Features of Honor for the American Sample.

\begin{tabular}{|c|c|c|}
\hline \multirow[b]{2}{*}{ Concept } & \multirow{2}{*}{$\frac{\text { Study I }}{\text { Percentage of participants }}$} & \multirow{2}{*}{$\frac{\text { Study } 2}{\text { Centrality ratings }}$} \\
\hline & & \\
\hline Doing the right thing & 14.95 & 6.05 \\
\hline Being respected & 14.95 & 5.73 \\
\hline Trustworthiness & 14.02 & 6.15 \\
\hline Being respectful & 13.08 & 5.96 \\
\hline To be looked up to & 13.39 & 5.40 \\
\hline To feel proud of oneself & 12.15 & 5.08 \\
\hline Honesty & I I.2I & 6.27 \\
\hline Integrity & 11.21 & 6.02 \\
\hline Self-respect & 10.28 & 5.54 \\
\hline Having accomplishments & 10.28 & 4.92 \\
\hline Having morals & 9.35 & 5.97 \\
\hline How a person feels about himself or herself & 9.35 & 4.96 \\
\hline Taking pride in one's own accomplishments & 7.48 & 5.02 \\
\hline Helping others & 6.54 & 5.83 \\
\hline Following one's own morals & 6.54 & 5.79 \\
\hline Having personal values & 6.54 & 5.68 \\
\hline How one acts & 6.54 & 5.58 \\
\hline Being hardworking & 6.54 & 5.51 \\
\hline Having achievements & 6.54 & 4.75 \\
\hline Loyalty & 5.61 & 6.12 \\
\hline Putting others first & 5.61 & 5.59 \\
\hline An individual's personality or character & 5.61 & 5.50 \\
\hline Being brave & 5.61 & 5.45 \\
\hline
\end{tabular}


Table 2. (continued)

\begin{tabular}{|c|c|c|}
\hline \multirow[b]{2}{*}{ Concept } & \multirow{2}{*}{$\frac{\text { Study I }}{\text { Percentage of participants }}$} & \multirow{2}{*}{$\frac{\text { Study } 2}{\text { Centrality ratings }}$} \\
\hline & & \\
\hline Being in the military & 5.61 & 4.77 \\
\hline Doing good things & 4.67 & 5.78 \\
\hline Dignity & 4.67 & 5.74 \\
\hline Having one's own beliefs & 4.67 & 5.39 \\
\hline Being respected for one's achievements & 4.67 & 5.08 \\
\hline Having respect & 3.74 & 5.90 \\
\hline Being dependable & 3.74 & 5.97 \\
\hline Being a responsible person & 3.74 & 5.96 \\
\hline Being reliable & 3.74 & 5.96 \\
\hline To be involved in community work & 3.74 & 5.93 \\
\hline Being admirable & 3.74 & 5.93 \\
\hline Truthfulness & 2.80 & 6.13 \\
\hline Not going back on your word & 2.80 & 6.08 \\
\hline Being faithful & 2.80 & 5.88 \\
\hline Doing good things for others & 2.80 & 5.88 \\
\hline To respect things & 2.80 & 5.83 \\
\hline Being just & 2.80 & 5.73 \\
\hline Being willing to sacrifice & 2.80 & 5.72 \\
\hline Selflessness & 2.80 & 5.58 \\
\hline Kindness & 2.80 & 5.55 \\
\hline Saving someone & 2.80 & 5.53 \\
\hline To be respected for what you are & 2.80 & 5.51 \\
\hline Excelling in school & 2.80 & 5.48 \\
\hline Being a leader & 2.80 & 5.46 \\
\hline Being strong & 2.80 & 5.45 \\
\hline To be respected for what you do & 2.80 & 5.44 \\
\hline Pride in one's family & 2.80 & 5.41 \\
\hline To be highly regarded & 2.80 & 5.27 \\
\hline Having goals & 2.80 & 5.22 \\
\hline Having self-esteem & 2.80 & 5.11 \\
\hline How someone presents himself or herself & 2.80 & 5.02 \\
\hline What a person is proud of & 2.80 & 4.54 \\
\hline To be smart & 2.80 & 4.07 \\
\hline Having ethics & 1.87 & 5.91 \\
\hline Being a good person & 1.87 & 5.84 \\
\hline Being dedicated & 1.87 & 5.83 \\
\hline Doing great deeds & 1.87 & 5.60 \\
\hline Keeping to one's ideals & 1.87 & 5.57 \\
\hline Not giving into temptations & 1.87 & 5.46 \\
\hline Doing something for society & 1.87 & 5.45 \\
\hline To be respectable in the community & 1.87 & 5.29 \\
\hline Listen to one's conscience & 1.87 & 5.27 \\
\hline How one holds himself or herself & 1.87 & 5.26 \\
\hline Wisdom & 1.87 & 5.25 \\
\hline Being confident & 1.87 & 5.23 \\
\hline Being worthy & 1.87 & 5.08 \\
\hline To make others proud & 1.87 & 4.82 \\
\hline Not cheating & 1.87 & 4.66 \\
\hline Being successful & 1.87 & 4.55 \\
\hline Having ability & 1.87 & 4.43 \\
\hline Staying healthy & 1.87 & 4.28 \\
\hline Winning an award & 1.87 & 4.16 \\
\hline
\end{tabular}

Note. Bold text refers to concepts that were spontaneously generated by the Turkish and American participants. For the percentage of participants in the Turkish sample, please refer to Table I. Centrality was rated on a I- to 7-point scale. 
Table 3. Means of Centrality Ratings for Unique Features Generated Within Each Cultural Context.

\begin{tabular}{|c|c|c|c|c|}
\hline Group & Features generated by TR participants & Features generated by U.S. participants & $t$ & $d$ \\
\hline Turkey & $5.16(.7 I)$ & $4.27(.89)$ & $33.79 * * *$ & I.II \\
\hline Northern United States & $5.04(.65)$ & $5.16(.71)$ & $8.08 * * *$ & 0.18 \\
\hline
\end{tabular}

Note. Standard deviations are provided in parentheses. $n$ (Turkey) $=334 ; n$ (Northern United States) $=275$.

$* * * p<.001$.

not to steal anything. The largest proportion of these items focus on moral behavior and self-respect. In the Northern United States, the features that were frequently mentioned (by $6.5 \%$ or more) and rated as highly central (rated 5.5 or higher) included doing the right thing, being respected, trustworthiness, being respectful, being honest, integrity, selfrespect, having morals, helping others, following one's own morals, having personal values, how one acts, and being hardworking. These items also reflect good behavior, but in contrast to the Turkish list, there is relatively little mention of specific moral behaviors. Instead, the moral code is reflected in vague generalities, such as do the right thing and having morals. In both groups, however, honesty, trustworthiness, and having personal values are viewed as central to the prototype of honor, along with self-respect.

In summary, the Turkish participants generated more features of honor than did Northern American participants, but the number of unique features generated in each group were similar. There was relatively little overlap in the unique features generated by the two groups, indicating differences in their cognitive representations of honor. One of the most noticeable differences was that the Turkish features were more likely than the Northern American features to indicate something that one should not do. There was also a greater agreement among Turkish participants on the specific features of honor compared with the Northern American participants.

\section{Study 2}

Study 2 examines the cultural similarities and differences in the centrality of the features of honor and their latent structure. We asked a new sample of participants in each cultural group to rate the items combined from the Turkish and Northern U.S. sets of items from Study $1 b$ to have a comprehensive catalog of features.

First, we examined the similarity between the Turkish and Northern American participants' centrality ratings of the combined set of features. Second, we examined each group's ratings of features generated by members of their own society compared with the features generated by members of the other society. We hypothesized that participants will rate the features unique to their own culture as more central to their concept of honor than features unique to the other cultural group. Third, we examined the latent structure of the ratings of the combined set of features by members of the two groups. We addressed two questions in these analyses: (a) Are the dimensions underlying the ratings by the two groups similar or different? and (b) If we find similar dimensions, are the ratings of the centrality of the dimensions similar in the two groups?

\section{Method}

Participants. The Turkish sample consisted of 334 (203 women) undergraduates from two different universities in Istanbul. The Northern U.S. sample consisted of 275 (177 women) European American undergraduates from a public northern university. Due to missing data, the sample sizes differ for some analyses.

Procedure and measures. The items administered to the two groups in Study $1 \mathrm{~b}$ were translated and backtranslated and combined into a single set of 117 items (items generated in both groups were listed only once). Participants rated the items using a 7-point scale $(1=$ this feature is an extremely poor indicator of having honor; $7=$ this feature is an extremely good indicator of having honor). The features were presented in two counterbalanced orders in the participants' native language.

\section{Results and Discussion}

Comparisons of ratings by the two groups. Examination of the association between the two group's ratings of the set of items revealed that the Turkish and Northern U.S. ratings were moderately highly correlated, $r(116)=.62, p<.001$. As hypothesized, participants rated the features generated by members of their own culture as more central to their prototypes of honor than features generated by the other cultural group, $F(1,607)=992.43, p<.001, \eta_{p}^{2}=.62$ (items generated in both settings were excluded; see Table 3 ). The difference in ratings of the items from the two countries was greater for the Turkish participants $(d=1.11)$ than for the Northern American participants $(d=0.18)$. Indeed, the Turkish participants' ratings of the American items were much lower than the Northern Americans' ratings of the Turkish items, $t(607)=11.91, p<.001, d=0.99$. This finding suggests that the Turkish conception of honor is more differentiated than that of Northern Americans.

Exploratory factor analysis. We conducted principal component analysis with oblique rotation separately within each 
Table 4. Rotated Factor Structure of Turkish and Northern American Centrality Ratings of Features of Honor from Turkey and the Northern US (Study 2).

\begin{tabular}{|c|c|c|c|c|c|c|c|c|}
\hline \multirow[b]{2}{*}{ Features } & \multicolumn{4}{|c|}{ Turkey } & \multicolumn{4}{|c|}{ Northern United States } \\
\hline & $\begin{array}{l}\text { Social Status/ } \\
\text { Respect }\end{array}$ & $\begin{array}{c}\text { Moral } \\
\text { Behavior }\end{array}$ & Self-Respect & Helping Others & $\begin{array}{l}\text { Social Status/ } \\
\text { Respect }\end{array}$ & $\begin{array}{l}\text { Moral } \\
\text { Behavior }\end{array}$ & Self-Respect & Helping Others \\
\hline One's position in the society & .811 & -.062 & .031 & .000 & .796 & .022 & -.038 & .052 \\
\hline To reach a certain status in the society & .805 & -.033 & .052 & -.002 & .858 & .051 & .052 & .075 \\
\hline How much the society values a person & .817 & .020 & .029 & -.022 & .817 & .023 & .095 & -.065 \\
\hline To be respectable in the community & .818 & .092 & .114 & -.167 & .672 & -.001 & -.042 & -.074 \\
\hline Being admirable & .798 & -.022 & .083 & -.015 & .457 & .092 & -.173 & -.161 \\
\hline Being appreciated & .726 & -.027 & .007 & .125 & .666 & -.052 & -.197 & -.053 \\
\hline $\begin{array}{l}\text { Not to have one's own truths to contradict with society's } \\
\text { truths }\end{array}$ & .659 & .047 & -.208 & .121 & .611 & -.040 & .036 & -.122 \\
\hline To be highly regarded & .708 & .061 & .005 & .091 & .722 & -.050 & -.116 & .001 \\
\hline To fit into customs and traditions & .593 & .119 & -.191 & .044 & .737 & .111 & .047 & .037 \\
\hline To make others proud & .609 & -.008 & .220 & -.028 & .612 & -.043 & -.057 & -.181 \\
\hline To be respected for what you do & .570 & -.015 & .219 & .107 & .556 & -.020 & -.211 & -.020 \\
\hline Winning an award & .594 & -.153 & .170 & .134 & .725 & .051 & -.019 & .024 \\
\hline Not being a hypocrite & .051 & .843 & -.040 & -.082 & -.153 & .537 & -.187 & -.086 \\
\hline Not telling lies & .030 & .745 & -.096 & .028 & .114 & .787 & .051 & .020 \\
\hline Keeping promises & .050 & .702 & .049 & .003 & -.062 & .545 & -.093 & -.153 \\
\hline Being just & -.174 & .658 & .158 & .212 & -.188 & .500 & -.125 & -.149 \\
\hline Not cheating & .079 & .690 & -.033 & .047 & .056 & .814 & .025 & .081 \\
\hline Honesty & .036 & .681 & .069 & .031 & -.035 & .698 & -.060 & .079 \\
\hline Not to use others for one's own benefit & -.046 & .685 & .067 & -.009 & .117 & .570 & .140 & -.125 \\
\hline Not to steal anything & -.030 & .638 & -.006 & .045 & .107 & .720 & -.003 & .001 \\
\hline To have one's own principles & -.069 & .133 & .721 & -.055 & -.120 & -.029 & -.745 & -.149 \\
\hline To apply one's own virtues & -.069 & -.105 & .714 & -.033 & -.064 & .244 & -.570 & .067 \\
\hline Not compromising one's own characteristics & .053 & .161 & .559 & -.172 & .009 & .065 & -.477 & -.056 \\
\hline What a person is proud of & .168 & .031 & .566 & -.145 & .251 & .133 & -.440 & .209 \\
\hline Having one's own beliefs & .071 & .010 & .611 & .023 & -.034 & -.043 & -.753 & -.006 \\
\hline Not to let oneself be oppressed by others & .039 & .022 & .566 & -.051 & -.077 & -.004 & -.520 & -.235 \\
\hline How one holds him/herself & -.022 & -.046 & .600 & .072 & .144 & .061 & -.612 & .111 \\
\hline Being confident & .112 & -.028 & .588 & .132 & .203 & .090 & -.463 & -.098 \\
\hline Being determined & .133 & $.08 \mathrm{I}$ & .567 & .108 & .201 & -.013 & $-.5 \mathrm{II}$ & -.127 \\
\hline Having self-esteem & -.007 & .089 & .654 & .178 & .253 & -.050 & -.577 & -.035 \\
\hline The value one gives to himself/herself & -.019 & -.066 & .696 & .116 & .270 & .028 & -.583 & .099 \\
\hline To be helpful to other people & -.043 & .178 & .040 & .785 & .120 & .208 & .011 & -.662 \\
\hline Doing good things for others & -.028 & .108 & -.039 & .770 & .001 & .209 & .052 & -.646 \\
\hline To be involved in community work & .072 & .001 & .103 & .709 & .274 & -.017 & .008 & -.714 \\
\hline Being willing to sacrifice & .122 & -.057 & .040 & .686 & -.103 & .042 & -.241 & -.515 \\
\hline Doing something for society & .172 & .087 & -.057 & .665 & .181 & -.034 & -.066 & -.686 \\
\hline
\end{tabular}

Note. Item labels in italicized font were generated by Turkish participants; item labels in bold font were generated by both Turkish and American participants. Loadings greater than .40 are in bold font.

cultural group to examine the dimensions that underlay lay conceptions of honor. An examination of the scree plots for both groups indicated that a four-factor solution was most fitting (Russell, 2002). To clarify the factors, we dropped items that loaded less than .40 on a factor or that loaded greater than .30 on more than one factor (as suggested by Fischer \& Fontaine, 2011). A new factor analysis with a final set of 36 items was conducted using oblique rotation; the rotated factors with pattern matrix coefficients are presented in Table 4.

The four-factor solution explained $52.9 \%$ of the variance in the ratings for Turkish participants and $49.8 \%$ of the variance for Northern Americans. Examination of the Northern American and Turkish factor structures reveals several similarities. In both groups, the first factor includes items such as "To reach a certain status in society," and "How much the society values a person." This factor reflects the notion of honor as social reputation and one's regard by others, and was labeled "Social Status/Respect." The second factor includes a variety of actions that one should or should not do, such as not cheating and being just. This factor reflects the importance of codes of personal conduct and was labeled "Moral Behavior."

The third factor includes items such as to have one's own virtues, the value one gives to himself/herself, and having self-esteem. It includes items that tap the importance of one's moral convictions and the feeling that one is a person worthy of respect; it was labeled "Self-Respect." The final factor includes items such as to be helpful to others and doing something for society. This factor reflects involvement in the welfare of others; it was labeled "Helping Others." The variances accounted for by these four factors were $27.6 \%, 11.5 \%$, 
Table 5. Centered Means, Standard Deviations, and Correlations Among Honor Factor Scores for Turkish and Northern American Participants (Study 2).

\begin{tabular}{|c|c|c|c|c|c|c|c|c|}
\hline \multirow[b]{2}{*}{ Factor } & \multirow{2}{*}{$\begin{array}{l}\text { Turkey } \\
M(S D)\end{array}$} & \multirow{2}{*}{$\frac{\text { United States }}{M(S D)}$} & \multirow[b]{2}{*}{$F$} & \multirow[b]{2}{*}{$d$} & \multicolumn{4}{|c|}{ Correlations Among Factors } \\
\hline & & & & & 1 & 2 & 3 & 4 \\
\hline I. Social Status/Respect & $-1.11 \quad(1.29)$ & $-1.0(1.09)$ & 1.18 & -.09 & $(.94, .93)$ & $.21 * *$ & $.45^{* *}$ & $.49 * *$ \\
\hline 2. Moral Behavior & $1.20(.82)$ & $.60(.7 I)$ & $91.88 * * *$ & .78 & $.23 * *$ & $(.88, .87)$ & $.24 * *$ & $.44 * *$ \\
\hline 3. Self-Respect & $-.02(.99)$ & $-.03(.77)$ & .06 & .01 & $.56 * *$ & $.45^{* *}$ & $(.87, .88)$ & $.23 * *$ \\
\hline 4. Helping Others & $-.07(1.14)$ & .44 ( . .79) & $39.55^{* * * *}$ & -.52 & $.42 * *$ & $.46^{* *}$ & $.48^{* *}$ & $(.88, .82)$ \\
\hline
\end{tabular}

Note. Within cultural group, factor scores were centered by subtracting the cultural group's grand mean from the averaged factor score. Correlations above the diagonal are for the Turkish participants $(n=334)$; those below the diagonal are for the American participants $(n=275)$. Values on the diagonal are the coefficient alphas for the Turkish and American samples. $*_{p}<.05 . *_{p}<.01 . *_{* *} p<.001$.

$9.3 \%$, and $4.6 \%$, respectively, among Turkish participants and $28.7 \%, 10.8 \%, 5.6 \%$, and $4.7 \%$ among Northern U.S. participants.

To determine whether this four-factor solution fit similarly for both cultural groups, we performed a Procrustes rotation. We set the Turkish factor structure as the normative group, and rotated the Northern U.S. factor structure toward the Turkish structure. Using the syntax provided by Fischer and Fontaine (2011), which calculates congruence coefficients, we found that the two factor structures were similar. The most stringent analysis revealed identity coefficients of .95 for Social Status/Respect, .93 for Moral Behavior, .94 for Self-Respect, and .88 for Helping Others. These values indicate an adequate to good similarity of these factors in these groups (see criterion by Van de Vijver \& Leung, 1997).

Mean differences in centrality and correlations of dimensions. We averaged the items for each factor to create a dimension score. Before comparing these means, we centered all the dimension scores on their own cultural group's grand mean to tackle group differences in scale use; the Turkish grand mean $(4.93, S D=.77)$ was lower than the Northern U.S grand mean $(5.25, S D=.63), t(607)=5.70, p<.001, d=.45$. As shown in Table 5, Turkish and Northern U.S participants viewed Moral Behavior as the most central to the concept of honor and Social Status/Respect as the least central. Repeated-measures ANOVA revealed a significant interaction between the dimensions and cultural group, $F(1,606)=$ 45.66, $p<.001, \eta_{p}^{2}=.07$. Comparisons across cultures revealed differences in the means of Moral Behavior (TR > US) and Helping Others (TR < US; see Table 5). ${ }^{4}$

These factors were somewhat more highly correlated in the Northern U.S. data than in the Turkish data. $R$-to- $z$ transformations showed that correlations of the SelfRespect factor with the Moral Behavior factor and the Helping Others factor were stronger among Northern Americans than among Turkish participants, $z s \geq-2.93, p \mathrm{~s}$ $<01$. There also was a marginally significant tendency for the correlation between the Social Status/Respect factor and the Self-Respect factor to be stronger among the Northern Americans than the Turkish participants, $z=$
$-1.81, p=.08$. Thus, the latent dimensions are less strongly differentiated among the Northern Americans than among the Turkish participants, suggesting that Northern Americans' conceptions of honor are not as clearly elaborated or complex as those of Turkish participants.

In summary, these results suggest that the Turkish conception of honor is more complex and differentiated than that of Northern Americans. The factor analysis revealed that honor is a multifaceted construct in Turkey and the Northern Unite States and that similar factor structures explain the ratings in both groups. These results extend the classic theorizing and definition of honor as a sense of self-worth and social respect (Pitt-Rivers, 1965) through the identification of the dimensions of moral behavior and helping others.

\section{Study 3}

Our final study examined whether the four dimensions identified in Study 2 replicate when people evaluate the personal importance of these features. At least theoretically, the dimensions underlying the prototype of honor could differ from those underlying individuals' views of the importance of these features to themselves. Replication of the dimensions would provide support for their importance at the individual level and would aid in the refinement of measures of these dimensions.

A second goal of this study was to establish the validity of these dimensions by assessing their relations to theoretically related constructs. We expected a measure of individual and family social respect, the Honor Values Scale (HVS; Rodriguez Mosquera et al., 2008), to be positively associated with these dimensions. Theoretically, the Social Status/ Respect dimension should relate positively to other measures that tap the importance of others' approval for self-worth and negatively to the perception that one's value as an individual is inalienable and independent of others' respect. We tap these constructs using the Others' Approval subscale of the Contingency of Self-Worth Scale (CSWS; Crocker, Luhtanen, Cooper, \& Bouvrette, 2003) and the Inalienable Worth measure (Leung \& Cohen, 2011). The Moral Behavior dimension encompasses a variety of actions related to the individual's belief that he or she is a moral or virtuous person. Thus, 
self-ratings on this dimension should be positively associated with the Virtue subscale of the CSWS (Crocker et al., 2003). Finally, we examined the association of the honor factors with a global measure of self-esteem (Rosenberg, 1965).

\section{Method}

Participants and procedure. The Turkish sample consisted of 287 (164 women) undergraduates from two universities in Istanbul and Ankara. The Northern U.S. sample consisted of 305 (191 women) European American undergraduates from a public northern university. Two Northern American and 6 Turkish participants were dropped for not following instructions. Due to missing data, the degrees of freedom may vary across analyses.

Measures. The questionnaires included the 36 features used in the final version of the honor factor analysis in Study 2 and related measures used to examine the validity of the honor dimensions. Except for the importance ratings of the honor features, participants completed the measures using a 7-point scale $(1=$ strongly disagree to $7=$ strongly agree $)$.

Honor features. Items reflecting honor features were slightly reworded to be more easily rated for their importance to the self. Participants indicated the importance of each item to themselves using a 4 -point scale $(0=$ not important at all to $4=$ extremely important).

HVS. The five-item HVS (Rodriguez Mosquera et al., 2008) taps the importance of one's own and one's family's social image (e.g., "It is important to me that others see me as someone who deserves respect" and "How others think of my family is important to me" $\alpha_{\mathrm{TR}}=.74, \alpha_{\mathrm{US}}=.79$ ).

Contingencies of Self-Worth scale. Participants responded to two subscales of the Crocker et al. (2003) CSWS that assess the extent to which an individual's sense of self-worth is based on Others' Approval (five items; for example, "I don't care what other people think of me [reversed]"), $\alpha_{\mathrm{TR}}=$ $.77 ; \alpha_{\mathrm{US}}=.78$, and virtue (five items; for example, "My selfesteem would suffer if I did something unethical"), $\alpha_{\mathrm{TR}}=.84$, $\alpha_{U S}=.85$. High scores indicate strong endorsement of others' approval or virtue as a basis of self-worth.

Inalienable Worth Scale. The four-item Inalienable Worth Scale measures the belief that an individual's value is inalienable rather than socially conferred (Leung \& Cohen, 2011). A sample item is "How others treat me is irrelevant to my worth as a person"; $\alpha_{\mathrm{TR}}=.69 ; \alpha_{\mathrm{US}}=.66$. Higher scores indicate greater endorsement of inalienable worth of the individual as opposed to the belief that worth is socially conferred.

Global self-esteem. Global self-esteem was assessed with the 10-item Rosenberg (1965) Self-Esteem scale (e.g., "I take a positive attitude toward myself"), $\alpha_{\mathrm{TR}}=.88 ; \alpha_{\mathrm{US}}=.87$.
Structural equivalence of measures. We examined the cross-cultural equivalence of these related measures using the recommendations of Van de Vijver and Leung (1997). The factorial agreement calculated using the most stringent identity index revealed identity coefficients greater than .98 for all the measures, indicating very high levels of factorial similarity across the two groups.

\section{Results and Discussion}

Confirmatory factor analysis (CFA). We conducted a confirmatory factor analysis using Mplus in which we specified the four-factor structure identified in Study 2. Using the combined sample, the initial results indicated that there was relatively poor fit of this model, comparative fit index (CFI) = .764, Root Mean Square Error of Approximation (RMSEA) $=.081$, and normed fit index $(\mathrm{NFI})=72.2$. Even after we dropped variables that loaded poorly (lower than .40 on any factor), the fit of the model was unacceptable, $\mathrm{CFI}=.884$, Standardized Root Mean Square Residual $($ SRMR) $=.06$, and NFI $=.84$.

Because the CFA revealed a poor fit of the data, we reasoned that perhaps the rewording of the items and the change in reference from "How well does this fit the prototype of honor?" to "How important is this to you?" may result in a different factor structure. Thus, we conducted exploratory factor analyses on these data. We first examined a four-factor structure (using PCA and varimax rotation) with the two groups combined. The factor structure was not as clear as in Study 2; there were many items that loaded on more than one factor, and the scree plot indicated that a three-factor solution was preferred. Thus, we reran the analyses with a three-factor solution.

This three-factor solution was much cleaner than the four-factor solution, and the factors mapped onto the Moral Behavior, Social Status/Respect, and Self-Respect factors identified in Study 2. The items from the Helping Others subscale primarily loaded on the Moral Behavior factor. These three factors explained $45.2 \%$ of the variance. This analysis revealed four items that loaded similarly on two factors or that failed to load strongly on any of the factors. These four items were dropped from the analyses, and the analyses were conducted separately within each cultural group. This step revealed that there were seven items that either loaded on different factors in the two groups or that loaded strongly on one of the factors for one group and not the other. In the interest of obtaining a clear factor structure that would be useful for scale development, we dropped these seven items and reran the PCA analysis using varimax rotation. ${ }^{5}$

This analysis revealed a clean structure with few double loadings more than .4 (see Table 6). In the Turkish data, the variance accounted for by the Moral Behavior, Social Status/ Respect, and Self-respect factors was $24.2 \%, 22.7 \%$, and $7.9 \%$, respectively, totaling $54.8 \%$. In the Northern U.S. data, the factors accounted for $29.4 \%, 14.8$, and $7.2 \%$ of the 
Table 6. Rotated Factor Structure of Turkish and Northern American Centrality Ratings of Combined Turkish and American Features of Honor (Study 3).

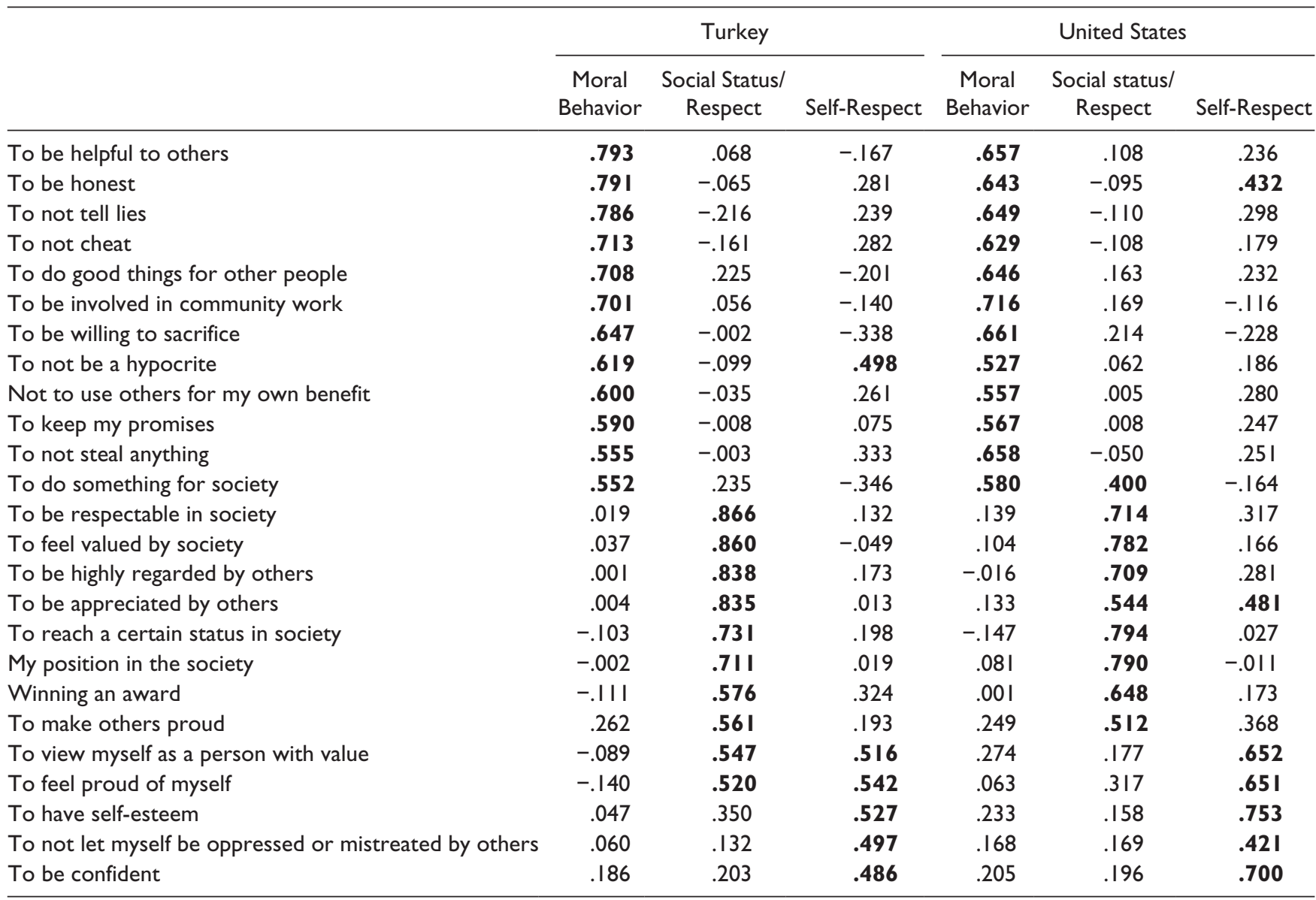

Note. Loadings greater than .40 are in bold font.

variance, respectively, totaling 51.5\%. The Procrustes analysis resulted in identity coefficients of .96 for the Moral Behavior factor and .95 for the Social Status/Respect factor, which indicate good factor similarity. The identity coefficient for the third factor, Self-Respect, was lower, $r=.88$, which is above the suggested cutoff of .85 for incongruence (Fischer \& Fontaine, 2011), but it does suggest that there is enough discrepancy in the factor loadings for the two groups to warrant caution.

Mean differences in importance and correlations of dimensions. We created indices for each dimension and examined their means and intercorrelations (see Tables 7 and 8). Before comparing the means of the subscales, we centered each subscale on the cultural group's grand mean to tackle potential group differences in scale use; the Turkish participants $(M=$ $2.96, S D=.46)$ rated the items slightly lower than did the Northern American participants $(M=3.03, S D=.45), t(591)$ $=2.06, p=.04, d=.15$. As shown in Table 7, the Turkish and Northern U.S. participants indicated that the items associated with Self-Respect were the most important and the items associated with Social Status/Respect were the least important to them. In contrast to the results of Study 2, there were no significant differences between the two groups in the endorsement of these dimensions. ${ }^{6}$

The correlations among the factors differed for the two groups (Table 8). Most notably, for the Turkish sample, the Moral Behavior factor did not correlate with the other two factors, whereas both of these correlations were significant for the Northern Americans. $R$-to- $z$ transformations revealed that the correlations with the Moral Behavior factor differed significantly for the two groups, zs $\geq 2.62, p s<.01$. The correlations between Self-Respect and the Social Status/Respect factors did not differ for the two groups, $z=0.79, n s$. One possible explanation for the lower correlations in Turkey is that in a tight society, such as Turkey, social norms for behavior are very strict (Gelfand et al., 2011) and moral behavior may be viewed as compulsory, given the honor code (Wikan, 2008). Therefore, one cannot be viewed as an honorable person without moral behavior, but doing what is expected morally may not necessarily enhance one's social standing or 
Table 7. Centered Means and Standard Deviations of Honor Factor Scores for Turkish and American Participants (Study 3).

\begin{tabular}{|c|c|c|c|c|}
\hline & Turkey & US & & \\
\hline Factor & $M(S D)$ & $M(S D)$ & $F$ & $d$ \\
\hline I. Social Status/Respect & $-.38(.79)$ & $-.43(.7 \mathrm{I})$ & .62 & .07 \\
\hline 2. Moral Behavior & $.09(.60)$ & $.09(.53)$ & .00 & .00 \\
\hline 3. Self-Respect & $.29(.60)$ & $.34(.52)$ & 1.02 & -.09 \\
\hline
\end{tabular}

Note. Within cultural group, factor scores were centered by subtracting the cultural group's grand mean from the averaged factor score. $* p<.05 . * * p<.01$. *** $p<.001$.

self-respect, because it is in response to strong social norms. In contrast, in the Northern United States, individuals who endorse the importance of moral behavior may also tend to base their self-respect and perceived social standing on that dimension ("It is important to me to be honest, which makes me worthy of respect").

Honor dimensions' associations with other measures. We assessed several related measures of social approval, selfregard, and virtue to examine the honor dimensions' convergent validity. Due to the intercorrelations among the dimensions, we tested these associations using hierarchical regression analyses. First, we combined the samples and conducted analyses in which the comparison measures were regressed on the honor dimensions, a dummy variable representing cultural group, and the interactions between each of the honor dimensions and the group variable. This allowed us to examine the unique relationship between each of the honor dimensions and the comparison measures, controlling for the other honor dimensions. Where there were significant interactions with the culture variable, we conducted separate analyses within each cultural group. ${ }^{7}$ Where there were significant Culture $\times$ Honor Dimension interactions, we present the regressions separately for each cultural group in Table 9.

HVS. When HVS was regressed onto the three honor dimensions, Social Status/Respect was the strongest predictor of HVS $(\beta=.53, p<.001)$ and Moral Behavior was also a significant predictor $(\beta=.19, p<.001)$. The Self-Respect subscale did not predict HVS, but there was a significant Culture $\times$ Self-Respect interaction, $\beta=-.26, p<.001 ; \beta_{\mathrm{TR}}$ $=-.16, \beta_{\mathrm{US}}=.17$ (Table 9). Given the positive bivariate correlation between the Self-Respect factor and honor values in the Turkish sample (Table 8), the negative beta for SelfRespect in the Turkish sample is likely due to multicollinearity between the factors.

Others' approval contingency of worth. This analysis revealed a significant main effect of cultural group $(\beta=$ $-.17, p<.001)$; Turkish participants were more likely to endorse the importance of others' approval for their selfworth than were Northern Americans. As hypothesized, the Social Status/Respect subscale was the most strongly related to endorsement of Others' Approval, $(\beta=.47, p<$ $.001)$. Self-Respect was negatively related $(\beta=-.30 ; p<$ $.001)$ and Moral Behavior was marginally related to the approval contingency $(\beta=.07, p<.08)$. None of the interaction terms was significant; thus, the association between the honor subscales and the approval contingency were similar for the two cultural groups.

Inalienable worth. We hypothesized that endorsement of the Inalienable Worth Scale (Leung \& Cohen, 2011) would be positively associated with Self-Respect but negatively associated with Social Status/Respect. This analysis supported that hypothesis, $\beta_{\text {Social Status }}=-.30, p<.001, \beta_{\text {Self-Respect }}=.32, p$ $<.001$. There was also a significant main effect of cultural group, $\beta=.25, p<.001$, which was qualified by significant interactions with Social Status/Respect and Self-Respect, $p$ s $<.03$. When the analyses were conducted separately within culture, the results revealed first that the honor subscales explained more variance in the Turkish responses (20\%) than in the Northern American responses (5\%; Table 9). Consistent with Leung and Cohen's (2011) theory of honor cultures, the Turkish participants who viewed Social Status/Respect as highly important more strongly rejected the notion that one's worth is inalienable, compared with Northern American participants.

Global self-esteem. As expected, the Self-Respect subscale significantly predicted self-esteem, $\beta=.27, p<.001$. There were no other significant main effects or interactions.

Virtue contingency of worth. As expected, the Moral Behavior subscale was the strongest predictor of the virtue contingency, $\beta=.50, p<.001$. The association between the other honor subscales and virtue were similar in strength but opposite in direction: Social Status/Respect $(\beta=.09, p<.03)$ was positively associated with endorsement of the Virtue contingency, but Self-Respect $(\beta=-.10, p<.02)$ was negatively associated with Virtue.

There were also significant interactions between Culture and Social Status/Respect $(\beta=.20, p<.001)$ and SelfRespect $(\beta=-.24, p<.001)$. As shown in Table 9, Social Status/Respect was positively associated and Self-Respect was negatively associated with Virtue in Turkey, but neither measure significantly predicted the importance of Virtue in the Northern United States. The Virtue items do not specify particular behaviors; instead, they leave it to the participant to define ethical or moral behavior. For Turkish participants, feelings of pride (as tapped by the Self-Respect subscale) may conflict with honor code virtues such as modesty or self-sacrifice. In the Northern United States, however, the idea that one's value is independent of one's behavior is 
Table 8. Correlations Among Honor Factors and the Theoretically Related Measures, Presented Separately by Cultural Group.

\begin{tabular}{|c|c|c|c|c|c|c|c|c|}
\hline & $\begin{array}{c}\text { Social Status/ } \\
\text { Respect }\end{array}$ & $\begin{array}{c}\text { Moral } \\
\text { Behavior }\end{array}$ & Self-Respect & $\begin{array}{l}\text { Honor } \\
\text { Values }\end{array}$ & $\begin{array}{l}\text { Approval } \\
\text { CSWS }\end{array}$ & $\begin{array}{l}\text { Virtue } \\
\text { CSWS }\end{array}$ & $\begin{array}{l}\text { Inalienable } \\
\text { Worth }\end{array}$ & Self-Esteem \\
\hline Social Status/Respect & - & .03 & $.52 * *$ & $.53 * *$ & $.38^{*}$ & .10 & -.23 & .05 \\
\hline Moral Behavior & $.24 * *$ & - & .05 & $.20 * *$ & .10 & $.46 * *$ & .03 & -.02 \\
\hline Self-Respect & $.47^{* *}$ & $.44^{* *}$ & - & $.17^{*}$ & -.07 & -.10 & $.20 * *$ & $.20 * *$ \\
\hline Honor Values & $.58 * *$ & $.32 * *$ & $.45^{* *}$ & - & $.40 * *$ & $.33 * *$ & $-.21 * *$ & .06 \\
\hline Approval CSWS & $.28 * *$ & .01 & -.03 & $.26 * *$ & - & $.32 * *$ & $-.62 * *$ & $-.26 * *$ \\
\hline Virtue CSWS & $.12 *$ & $.55^{* *}$ & $.28 * *$ & $.28 * *$ & .07 & - & -.10 & $-.18 * *$ \\
\hline Inalienable Worth & -.03 & $.14^{*}$ & $.17 * *$ & .05 & $-.61 * *$ & $.17^{*}$ & - & $.21 * *$ \\
\hline Self-Esteem & $.20 * *$ & $.18^{* *}$ & $.34 * *$ & $.23 * *$ & $-.21 * *$ & $.12^{*}$ & $.33 * *$ & - \\
\hline
\end{tabular}

Note. Correlations for the Turkish sample are above the diagonal and Northern US correlations are below the diagonal. CSWS = Contingency of SelfWorth Scale.

$* p<.05 . * * p<.01$.

Table 9. Regression Analysis of the Associations of the Honor Factors With Other Related Measures (Study 3).

\begin{tabular}{|c|c|c|c|c|c|c|c|c|}
\hline \multirow[b]{2}{*}{ Outcome measure } & \multicolumn{4}{|c|}{ Turkey } & \multicolumn{4}{|c|}{ United States } \\
\hline & $b$ & SE & $\beta$ & $R^{2}$ & $b$ & SE & $\beta$ & $R^{2}$ \\
\hline \multicolumn{9}{|l|}{ Honor Values Scale } \\
\hline Constant & 5.81 & .06 & & $.33 * * *$ & 5.62 & .06 & & $.39 * * *$ \\
\hline Social Status/Respect & .67 & .06 & $.61 * * *$ & & .58 & .06 & $.47 * * *$ & \\
\hline Moral Behavior & .28 & .07 & $.19 * * *$ & & .21 & .08 & $.13^{*}$ & \\
\hline Self-Respect & -.24 & .08 & $-.16 * *$ & & .29 & .09 & $.17^{* *}$ & \\
\hline \multicolumn{9}{|l|}{ Inalienable Worth } \\
\hline Constant & 4.20 & .08 & & $.20 * * *$ & 3.94 & .09 & & $.05 *$ \\
\hline Social Status/Respect & -.65 & .09 & $-.46 * * *$ & & -.22 & .10 & $-.15^{*}$ & \\
\hline Moral Behavior & .03 & .10 & .02 & & .18 & .13 & .09 & \\
\hline Self-Respect & .83 & .12 & $.45^{* * * *}$ & & .41 & .14 & $.20 * *$ & \\
\hline \multicolumn{9}{|l|}{ Virtue CSWS } \\
\hline Constant & 4.85 & .09 & & $.26 * * *$ & 4.96 & .08 & & $.30 * * *$ \\
\hline Social Status/Respect & .34 & .09 & $.22 * * * *$ & & -.06 & .08 & -.05 & \\
\hline Moral Behavior & .96 & .11 & $.46 * * *$ & & .99 & .10 & $.53 * * *$ & \\
\hline Self-Respect & -.49 & .12 & $-.24 * * *$ & & .13 & .11 & .07 & \\
\hline
\end{tabular}

Note. Variables were centered using within-culture means prior to analyses. CSWS = Contingency of Self-Worth Scale.

$* p<.05 . * * p<.01 . * * * p<.001$.

pervasive, which may account for the null association between Virtue and Self-Respect.

\section{General Discussion}

Research evidence and theoretical accounts of honor point to differing definitions of the construct in differing cultural contexts. These studies first sought to identify the central and peripheral features of honor reported by lay people in a traditional honor culture (Turkey) and a nonhonor or dignity culture (Northern United States). Studies $1 \mathrm{a}$ and $1 \mathrm{~b}$ revealed substantial differences in the two groups at the level of the individual features that characterize honor. Only 16 of 145 total features were generated by members of both groups. Moreover, the features generated by Turkish participants included more specific statements about what one should not do (e.g., don't lie), whereas the Northern American features focused more on nonspecific positive aspects of behavior (e.g., do the right thing). Turkish people may be especially sensitive to these negative features of honor because honor is perceived to be easily lost and must be aggressively defended when attacked.

Second, we investigated whether there are meaningful dimensions underlying those features, and whether they differed across the two cultural groups. Factor analyses revealed that there were three common factors that explained substantial variance in the centrality ratings (Study 2) and the personal importance ratings (Study 3 ) of the combined Turkish and American features. These common dimensions represent Social Status/Respect, Moral Behavior, and Self-Respect, and the factor loadings were similar across the two cultures. These findings support the dual theory of honor that includes 
self-worth and social recognition (Pitt-Rivers, 1965; Wikan, 2008) and extend it by highlighting the importance of moral behavior for understanding honor. In short, honor is not simply respecting oneself and being respected by others. Instead, honor is the self- and social-esteem that has good and proper behavior (and not simply status, celebrity, or wealth) as its foundation.

Interestingly, the ranking of the centrality of these dimensions for the prototype of honor in Study 2 differed from the rankings of personal importance in Study 3. Northern European American and Turkish participants rated Moral Behavior as the most central and Social Status/Respect as the least central to the prototype of honor in Study 2. In Study 3, however, Self-Respect was the most personally important dimension (and social status/respect was again the least important). When people consider the cognitive representation of honor, they may be thinking about what people in general should or ought to do. When considering their own values, however, they seem to care the most about the features that provide a sense of personal worth. This evidence that people weigh information differently when evaluating their own or others' honor is consistent with a recent demonstration that participants' own evaluations of an honor-related situation may not overlap with their perceptions of how others would evaluate that situation (Cross, Uskul, Gerçek-Swing, Sunbay, \& Ataca, 2013).

It may be surprising that the Social Status/Respect dimension was the least central in these ratings, given its prominence in much of the contemporary theories of honor cultures (Bowman, 2006; Nisbett \& Cohen, 1996; Pitt-Rivers, 1965; Salzman, 2008; Wikan, 2008). In Turkey today, the importance of this aspect of honor is contentious. Although honor is a central value in Turkey, some people point to family killings of women who are accused of infidelity or promiscuity as the consequence of too much concern for reputation and social respect (Pope, 2012). In addition, young people living in urban spaces, such as those recruited in the current studies, may be in a life stage that involves challenging social norms and traditions; older, rural, or less educated adults may have responded differently. Despite reporting that they care less about others' respect than about self-respect or moral behavior, Turkish participants may behave quite differently when strong situations require that they actively defend their honor in front of others. For researchers, this finding calls attention to the possibility that some people will reject their culture's core values and react against researchers' attempts to assess these values (see Leung \& Cohen, 2011). Ultimately, findings that contradict theoretical conceptions of a phenomenon or previous research prompt critical thinking and further investigation that can modify or extend the existing theories.

The fourth objective of these studies was to examine whether these dimensions were associated with theoretically relevant constructs similarly in the two cultural groups. SelfRespect, Social Status/Respect, and Moral Behavior factors were associated in predictable ways with measures of other related constructs (e.g., self-esteem, Inalienable Worth Scale, and contingencies of worth), but some of these associations varied across cultures: The Social Status/Respect subscale was more strongly related to other measures among Turkish participants than among Northern U.S. participants. Thus, although the Social Status/Respect dimension was the least important to participants, these results demonstrate that it is more relevant to other attitudes and beliefs in a traditional honor culture than in a dignity culture, where the opinions of others are minimized.

Do the similarities described above suggest that the Northern United States should not be considered a dignity culture? That would be a premature conclusion given the current data. Instead, these studies reveal that lay conceptions of honor in a dignity culture share some underlying similarities with those found in a culture of honor (despite considerable differences at the level of the specific features). Consequently, honor may fit the definition of an existential universal (Norenzayan \& Heine, 2005). An existential universal is a phenomenon (e.g., a tool, construct, etc.) that exists in multiple cultures but is not necessarily used in the same way or accessible in the same situations across cultures. The combined evidence suggests that honor is a construct that exists in both of these cultures (and likely in many more), but it is more highly elaborated in Turkey than in the Northern United States, and it is likely to motivate behavior differently in these cultural contexts (see Uskul, Oyserman, Schwarz, Lee, \& Xu, 2013).

\section{Contribution to Theory and Research}

Theories of a phenomenon that lose sight of lay conceptions risk being overly narrow and neglecting key elements of the phenomenon. Yet, exclusive focus on the lay prototypes of a phenomenon lacks the rigor and connections to other related theoretical formulations found in good theories (Gregg et al., 2008). Thus, the inclusion of a prototype analysis into the literature on honor cultures can provide enhanced coverage of the concept that may lead to testable hypotheses and new theoretical developments. Our findings highlight the importance of moral behavior for a thorough understanding of honor. The role of moral behavior in cultures of honor has tended to be understated (or assumed) in much social-psychological research (but see Leung \& Cohen, 2011; Rodriguez Mosquera et al., 2008). The moral behavior items identified in these analyses may prove useful in future measures. In addition, the specific features generated by these participants differed in their orientation toward avoidance of specific negative behaviors (e.g., not to tell lies, generated by Turkish participants) or approaching positive behaviors (e.g., doing the right thing, generated by Northern American participants). This finding suggests a cultural difference in regulatory focus, which may underlie other cultural differences in honor-related behavior (Higgins, 1996). Thus, this prototype analysis points out potentially useful descriptive elements of 
honor and points to ways to integrate other theories into further research.

Second, these studies expand research on honor beyond the focus on aggression and reciprocity that has tended to dominate much of the research (at least in the United States). In particular, these results focus on positive aspects of honor and illustrate how people may mean different things when they claim to be acting in the name of honor. When the protestors at Gezi Park in Istanbul claimed that attacks on their honor was partly what propelled them to act (e.g., Oz, 2013), it is unclear whether self-respect, the opinions of others, or a desire to behave morally (or all three) motivated their behavior. The three dimensions are interrelated, but further research into their differential influence on specific behaviors as well as on individual differences in the strength of the three dimensions would provide a more nuanced understanding of honor.

Finally, these data can form the foundation of further research on related lay prototypes. We hope that by reporting the specific features generated, their frequencies, and their prototypicality ratings, we provide useful information for other researchers who wish to extend these findings to other societies (e.g., to the lay prototypes of members of other honor cultures, such as the Southern United States) or to compare these findings to the prototypes of other cultural constructs, such as face (Leung \& Cohen, 2011).

\section{Limitations}

The prototype approach is limited in its reliance on explicit, verbal reports, which can be swayed by factors such as the context of data collection. Most of the students at these universities are living in residence halls and apartments far from their families. The university research context may focus attention on individual aspects of honor more than on family honor, which may explain the unexpectedly small number of family- or community-related features generated in Turkey.

One problem with comparisons of two cultural groups is that they may differ on many dimensions in addition to the dimension under investigation. Although our samples were generally similar in age and SES, they differed in terms of their religious heritage and degree of religious devotion. As noted in the footnotes, the Turkish samples tended to be more devout than the U.S. samples; furthermore, religious devotion was related to the moral behavior dimension in Studies 2 and 3 in the combined samples. Most religions encourage virtuous, upright behavior; thus, this association is unsurprising. Yet, religious devotion was not strongly related to the other components of honor. Some people have associated honor-related behavior (such as honor killings) with religion, but the existing anthropological research disputes that belief (Wikan, 2008). Our findings suggest that this perceived association between religion and honor may lie in the shared importance of moral behavior. It would be intriguing to further explore the ways that religious beliefs and honor-related ideologies interact to influence behavior.

Moreover, this work did not uncover gendered dimensions of honor, which has been the focus of other researchers (e.g., Barnes, Brown, \& Osterman, 2012; Rodriguez Mosquera, Manstead, \& Fischer, 2002b; Vandello et al., 2009). The gender differences in these studies were inconsistent (see footnotes) except for one finding: Men rated moral behavior as less central to the prototype of honor (Study 2) and less personally important (Study 3) than did women. There are many double standards in cultural norms and roles for men and women, and women may intuit that they have more to lose from moral missteps than do men. Because we did not directly ask for gendered features of honor, these findings may understate the importance of gendered social roles in honor-related behaviors.

Finally, our work sampled individuals from one honor culture, Turkey, and one nonhonor culture, Northern United States. We do not claim that these two groups represent all honor and nonhonor cultures, respectively, or that the observed dimensions of honor would apply to other cultural groups that have different histories and values. Further research is needed to investigate the replicability of the current work.

\section{Conclusion}

These studies of lay prototypes of the construct of honor in Turkey and in the Northern United States reveal differences at the level of specific features but similarities in the primary underlying dimensions of Self-Respect, Moral Behavior, and Social Status/Respect. Researchers investigating the influence of honor on behavior will benefit from closer attention to the importance of moral behavior (and to how moral behavior is understood). The tripartite nature of honor uncovered in these studies helps observers and scholars alike understand how opposing behaviors and responses to situations can be attributed to honor. In the Gezi Park uprisings, protestors seemed to view their behavior as driven by personal honor, whereas politicians argued that the protests harm the country's respect in the eyes of others. Ultimately, research into the positive motivational force of honor on achievement, moral behavior, or altruism may help bring an end to some of the tragedies of honor, such as honor killings.

\section{Declaration of Conflicting Interests}

The author(s) declared no potential conflicts of interest with respect to the research, authorship, and/or publication of this article.

\section{Funding}

The author(s) disclosed receipt of the following financial support for the research, authorship, and/or publication of this article: This 
research was supported by the U.S. National Science Foundation Grant BCS0646360 awarded to Susan E. Cross and Ayse K. Uskul.

\section{Notes}

1. In each study, we conducted a MANOVA on these background variables. The Turkish participants tended to be older than the Americans, $.40 \leq d \mathrm{~s}<.60$ (except in Study 2, where there was no significant difference). Age was not a significant predictor in any of our analyses, so we do not report it further. The Turkish students also reported higher levels of religious devotion than did the Americans, $.17<d \mathrm{~s}<.5$. Differences in socioeconomic status (SES) were more inconsistent: In Studies 1a and 2, there were no significant differences, whereas there were small differences in Studies $1 \mathrm{~b}$ and 3, with the Americans reporting somewhat higher levels of SES than the Turkish participants, $.12<d \mathrm{~s}<.26$. Participants responded to the SES and religious devotion items using Likert-type scales, which are susceptible to reference group effects, so we urge caution in interpretation of any mean differences across cultures (Heine, Lehman, Peng, \& Greenholtz, 2002).

2. Namus is typically defined as women's sexual honor that presupposes certain moral and physical qualities (see Sev'er \& Yurdakul, 2001). It can also mean having integrity and being reliable and upright.

3. We examined gender differences in the generation of the specific features. In Turkey, there was a single feature (to fit into the rules of the society) that was generated significantly more frequently by women than by men $\left(\chi^{2}=3.94, p<.05\right)$. Among Americans, there were three items that were generated more frequently by women than by men (being respectful, self-respect, and being in the military), $\chi^{2} \geq 4.97, p s<.03$. Given that there were 145 analyses conducted, these four differences are likely due to chance alone.

4. A MANOVA conducted on the four factors revealed significant gender differences for Social Status and Respect, $F(1,602)=$ 7.53, $p<.01$, and for Moral Behavior, $F(1,602)=6.17, p<$ .02 . In both the cases, men rated the items in the factor as less central to the prototype of honor than did women: for Social Status/Respect, $M_{\text {men }}=-1.22, M_{\text {women }}=-.96, d=.22$; for Moral Behavior, $M_{\text {men }}=.83, M_{\text {women }}=.97, d=.16$. When the centered factors were regressed individually onto cultural group, religious devotion, and SES (hierarchically), religious devotion did not mediate the effects of culture on Moral Behavior or Helping Others. Religious devotion was, however, a significant predictor of Social Status/Respect $(\beta=.12, p<.01)$, Moral Behavior $(\beta$ $=.12, p<.01)$, and Helping Others $(\beta=.11, p<.01)$, but not Self-Respect. SES did not significantly predict any of the factor scores.

5. The 11 items that were dropped were being admirable, not to have one's own truths contradict society's truths, to fit into customs and traditions, to be respected for what you do, being just, to have one's own principles, to apply one's own virtues, not compromising one's own characteristics, having one's own beliefs, how one holds himself or herself, being determined.

6. When the centered factors were regressed individually onto cultural group, religious devotion, and SES, religious devotion was a significant predictor only of Moral Behavior $(\beta=.32, p<.001)$. SES was a significant predictor of the personal importance of Social Status/Respect $(\beta=.12, p<.01)$ and Moral Behavior $(\beta=$
$-.08, p<.08)$. A MANOVA of the three honor factors revealed significant gender differences in the importance of Moral Behavior, $F(1,588)=32.02, p<.001, \eta_{p}^{2}=.05$, and in the importance of Self-Respect, $F(1,588)=33.47, p<.001, \eta_{p}^{2}=.054$. Women evaluated both the dimensions as more important than did men.

7. Additional analyses conducted within each culture revealed that these associations were not moderated by gender.

\section{References}

Aron, A., \& Westbay, L. (1996). Dimensions of the prototype of love. Journal of Personality and Social Psychology, 70, 535-551.

Barnes, C. D., Brown, R. P., \& Osterman, L. L. (2012). Don't tread on me: Masculine honor ideology in the US and militant responses to terrorism. Personality and Social Psychology Bulletin, 38, 1018-1029.

Bowman, J. (2006). Honor: A history. New York, NY: Encounter Books.

Cantor, N., Mischel, W., \& Schwartz, J. (1982). A prototype analysis of psychological situations. Cognitive Psychology, 14, 45-77.

Cohen, D., Nisbett, R. E., Bowdle, B. F., \& Schwarz, N. (1996). Insult, aggression, and the southern culture of honor: An experimental ethnography. Journal of Personality and Social Psychology, 70, 945-960.

Crocker, J., Luhtanen, R. K., Cooper, M. L., \& Bouvrette, S. A. (2003). Contingencies of self-worth in college students: Measurement and theory. Journal of Personality and Social Psychology, 85, 894-908.

Cross, S., Uskul, A. K., Gerçek-Swing, B., Sunbay, Z., \& Ataca, B. (2013). Confrontation vs. withdrawal: Cultural differences in responses to threats to honor. Group Processes and Intergroup Relations, 16, 345-362.

Fehr, B. (1988). Prototype analysis of the concepts of love and commitment. Journal of Personality and Social Psychology, 55, 557-579.

Fehr, B. (1994). Prototype-based assessment of laypeople's views of love. Personal Relationships, 1, 309-331.

Fehr, B. (2005). The role of prototypes in interpersonal cognition. In M. W. Baldwin (Ed.), Interpersonal cognition (pp. 180-205). New York, NY: Guilford.

Fehr, B., \& Russell, J. A. (1991). The concept of love viewed from a prototype perspective. Journal of Personality and Social Psychology, 60, 425-438.

Fischer, R., \& Fontaine, J. R. J. (2011). Methods for investigating structural equivalence. In D. Matsumoto \& F. J. R. van de Vijver (Eds.), Cross-cultural research methods in psychology (pp. 179-215). New York, NY: Cambridge University Press.

Gelfand, M. J., Raver, J. L., Nishii, L., Leslie, L. A., Lun, J., Lim, B. C., ... Yamaguchi, S. (2011). Differences between tight and loose cultures: A 33-nation study. Science, 332, 1100-1104. doi:10.1126/science.1197754

Gregg, A. P., Hart, C. M., Sedikides, C., \& Kumashiro, M. (2008). Everyday conceptions of modesty: A prototype analysis. Personality and Social Psychology Bulletin, 34, 978-992. doi:http://dx.doi.org/10.1177/0146167208316734

Hassebrauck, M. (1997). Cognitions of relationship quality: A prototype analysis of their structure and consequences. Personal Relationships, 4, 163-185. 
Hassebrauck, M., \& Fehr, B. (2002). Dimensions of relationship quality. Personal Relationships, 9, 253-270.

Heine, S. J., Lehman, D. R., Peng, K., \& Greenholtz, J. (2002). What's wrong with cross-cultural comparisons of subjective Likert scales? The reference-group effect. Journal of Personality and Social Psychology, 82, 903-918. doi:10.1037/0022-3514.82.6.903

Henry, P. J. (2009). Low status compensation: A theory for understanding the role of status in cultures of honor. Journal of Personality and Social Psychology, 97, 451-466.

Higgins, E. T. (1996). The "self digest": Self-knowledge serving self-regulatory functions. Journal of Personality and Social Psychology, 71, 1062-1083. doi:http://dx.doi. org/10.1037/0022-3514.71.6.1062

Kardam, F. (2005). The dynamics of honor killings in Turkey. Ankara, Turkey: United National Development Programme.

Kearns, J. N., \& Fincham, F. D. (2004). A prototype analysis of forgiveness. Personality and Social Psychology Bulletin, 30, 838-855.

Leung, A. K.-Y., \& Cohen, D. (2011). Within- and between-culture variation: Individual differences and the cultural logics of honor, face, and dignity cultures. Journal of Personality and Social Psychology, 100, 507-526.

Miller, W. I. (1993). Humiliation. Ithaca, NY: Cornell University Press.

Nisbett, R. E., \& Cohen, D. (1996). Culture of honor: The psychology of violence in the South. Boulder, CO: Westview Press.

Norenzayan, A., \& Heine, S. J. (2005). Psychological universals: What are they and how can we know? Psychological Bulletin, 131, 763-784.

Oz, C. (2013, June 11). I can never trust the Turkish police and government again. The Guardian. Available from http://www. theguardian.com

Pitt-Rivers, J. (1965). Honor and social status. In J. G. Peristiany (Ed.), Honor and shame: The values of Mediterranean society (pp. 19-78). London, England: Weidenfeld \& Nicolson.

Pope, N. (2012). Honor killings in the twenty-first century. New York, NY: Palgrave Macmillan.

Rodriguez Mosquera, P. M., Fischer, A. H., Manstead, A. S. R., \& Zaalberg, R. (2008). Attack, disapproval, or withdrawal? The role of honor in anger and shame responses to being insulted. Cognition \& Emotion, 22, 1471-1498.

Rodriguez Mosquera, P. M., Manstead, A. S. R., \& Fischer, A. H. (2002a). Honor in the Mediterranean and Northern Europe. Journal of Cross-Cultural Psychology, 33, 16-36.

Rodriguez Mosquera, P. M., Manstead, A. S. R., \& Fischer, A. H. (2002b). The role of honor concerns in emotional reactions to offenses. Cognition \& Emotion, 16, 143-163.
Rosch, E. (1975). Cognitive reference points. Cognitive Psychology, 7, 532-547.

Rosenberg, M. (1965). Society and the adolescent self-image. Princeton, NJ: Princeton University Press.

Russell, D. (2002). In search of underlying dimensions: The use (and abuse) of factor analysis in PSPB. Personality and Social Psychology Bulletin, 28, 1629-1646.

Salzman, P. C. (2008). Culture and conflict in the Middle East. Amherst, NY: Humanity Books.

Sev'er, A., \& Yurdakul, G. (2001). Culture of honor, culture of change: A feminist analysis of honor killings in rural turkey. Violence Against Women, 7, 964-998.

Shaver, P. R., Murdaya, U., \& Fraley, R. C. (2001). Structure of the Indonesian emotion lexicon. Asian Journal of Social Psychology, 4, 201-224. doi:http://dx.doi.org/10.1111/1467839X.00086

Shaver, P. R., Wu, S., \& Schwartz, J. C. (1992). Cross-cultural similarities and differences in emotion and its representation: A prototype approach. In M. S. Clark (Ed.), Review of personality and social psychology (Vol. 13, pp. 175-212). Newbury Park, CA: SAGE.

Smith, K. D., Turk Smith, S., \& Christopher, J. C. (2007). What defines the good person? Cross-cultural comparisons of experts' models with lay prototypes. Journal of Cross-Cultural Psychology, 38, 333-360.

Turkish President Warns of Country's Image Damage. (2013, June 18). Global Times. Available from www.globaltimes.cn

Uskul, A. K., Cross, S. E., Sunbay, A., Gerçek-Swing, B., \& Ataca, B. (2012). Honor bound: The cultural construction of honor in Turkey and the Northern US. Journal of Cross-Cultural Psychology, 43, 1131-1151.

Uskul, A. K., Oyserman, D., Schwarz, N., Lee, S. W., \& Xu, A. J. (2013). How successful you have been in life depends on the response scale used: The role of cultural mindsets in pragmatic inferences drawn from question format. Social Cognition, 31, 222-236.

Vandello, J. A., Cohen, D., Grandon, R., \& Franiuk, R. (2009). Stand by your man: Indirect cultural prescriptions for honorable violence and feminine loyalty. Journal of Cross-Cultural Psychology, 40, 81-104.

Van de Vijver, F. J. R., \& Leung, K. (1997). Methods and data analysis for cross-cultural research. Newbury Park, CA: SAGE.

Wikan, U. (2008). In honor of Fadime: Murder and shame. Chicago, IL: University of Chicago Press. 